\title{
PENGEMBANGAN E-MODUL FORMAT EPUB UNTUK PEMBELAJARAN MATEMATIKA KELAS X PADA MATERI TRIGONOMETRI
}

\author{
Wenni Meliana \\ Madrasah Aliyah Negeri 1 Banjarmasin \\ Email: wennichess@gmail.com
}

\begin{abstract}
Website : https://jurnal.uin-antasari.ac.id/index.php/ptkpend/index Received: 30 Juni 2020; Accepted: 25 Juli 2020; Published: 27 Juli 2020
\end{abstract}

\begin{abstract}
This research is descriptive research which has purpose to describe the development mathematic teaching trigonemtri, effect student in the learning and know student respon with emodul trigonemtri. Emodel trigonemtri is trigonemtri on the module can with student your device that is computer, laptop and mobile phone. Research Methode is research and development with ADDIE (Anaysis, Design, Development, Implemantation and Evaluation) modle. Research in Madrasah Aliyah Negeri 1 Banjarmasin and Grade X Social Scoence Program 1 experiment class and Grade X Social Science Program 2 Program 2 control class, that genap semester year 2018/2019. The result of research is (1) Trigonemteri module is valid nilai expert 85,42 good category, (2) Trigonemtri module that is effective with learning the difference test nilai experiment and control 18, 26, Complete experiment class and control class 84, 85\% passing grade student, (3) Student respon with to use module trigonemtri $81,82 \%$ good category. The result module trigonemetri eligible criteria and help learning and use student manual.
\end{abstract}

Key Words: e-modul; epub; ADDIE module

\begin{abstract}
ABSTRAK
Penelitian ini bertujuan mengembangkan emodul format epub untuk pembelajaran matematika pada materi trigonometri, menguji keefektifannya dalam pembelajaran, serta mengetahui respon siswa terhadap penggunaan emodul trigonometri. Emodul trigonometri adalah modul berisi materi trigonometri yang bisa digunakan pada perangkat digital yaitu komputer, laptop, dan HP. Metode penelitian yang digunakan yaitu penelitian dan pengembangan dengan model ADDIE (Analysis, Design, Development, Implementation, dan Evaluation). Penelitian dilaksanakan di kelas X IPS 1 sebagai kelas eksperimen subyek ujicoba produk, dan kelas X IPS 2 MAN 1 Banjarmasin sebagai kelas kontrol, pada semester genap tahun pelajaran 2018/2019. Hasil yang diperoleh dari penelitian ini adalah (1) Emodul Trigonometri dinyatakan valid oleh ahli dengan nilai 85,42 kategori sangat baik, (2) Emodul Trigonometri dinyatakan efektif dalam pembelajaran dengan perbedaan selisih rata-rata nilai tes antara kelas eksperimen dan kelas kontrol sebesar 18,26, Untuk ketuntasan klasikal kelas eksperimen sebesar $84,85 \%$ siswa tuntas atau mencapai KKM, (3) Hasil respon siswa terhadap penggunaan emodul trigonometri sebesar $81,82 \%$ termasuk kategori baik. Secara keseluruhan, emodul trigonometri memiliki kriteria layak, dapat dijadikan sebagai penunjang proses belajar siswa yang dapat digunakan secara mandiri.
\end{abstract}

Kata Kunci: e-modul; epub; model ADDIE

\section{PENDAHULUAN}

Belajar di sekolah bukan hanya sekedar rutinitas, namun dengan belajar maka siswa diharapkan memperoleh manfaat yang baru baik berupa pengetahuan, keterampilan, ataupun sikap (Rohman, 2018). Proses belajar mengajar di sekolah, pemanfaatan media, metode yang 
digunakan, fasilitas penunjang pembelajaran, sumber belajar yang inovatif, sangat mempengaruhi terhadap apa yang diperoleh siswa selama di sekolah. Guru harus menyajikan pelajaran dengan sebaikbaiknya agar tercapai tujuan pembelajaran yang efektif. Sehingga pemilihan model, strategi, dan metode pembelajaran perlu dipertimbangkan dengan tepat agar dapat memenuhi kebutuhan belajar, dapat meningkatkan motivasi belajar siswa serta dapat meningkatkan hasil belajar siswa (Sundayana, 2015). Guru dituntut untuk merubah orientasi pengajaran yang awalnya berpusat pada guru (teacher centered) menjadi berpusat pada siswa (student centered).

Pemerintah telah memberlakukan penerapan kurikulum 2013 sesuai dengan perkembangan abad 21 yang menuntut terjadinya perubahan paradigma pendidikan yang semula hanya mengajarkan ilmu, pengetahuan, dan keterampilan kepada siswa, menjadi pendidikan yang membelajarkan kompetensi yang dikenal sebagai kemampuan literasi, keterampilan abad 21 atau diistilahkan 4C (Communication, Collaboration, Critical Thinking dan Problem Solving), penguatan pendidikan karakter (PPK) serta HOTS (keterampilan berpikir tingkat tinggi).Kurikulum 2013 mengharuskan guru mampu mengimplementasikannya pada proses pembelajaran (Darsono, 2017). Penerapan teknologi, informasi dan komunikasi secara terintegrasi, sistematis, efektif dan efisien sesuai kondisi pada implementasi kurikulum 2013 merupakan tantangan yang harus dijawab semua guru termasuk guru matematika dalam merancang, melaksanakan dan mengevaluasi pembelajaran menyongsong generasi emas Indonesia tahun 2045.

Permasalahan yang ditemui adalah belum lengkapnya buku pelajaran kurikulum 2013 yang tersedia di perpustakaan sekolah, buku kurikulum 2013 yang disediakan pemerintah baik versi cetak ataupun ebook masih memiliki kelemahan yaitu latihan soal yang disediakan masih sedikit dan belum interaktif, pembelajaran matematika yang masih monoton, tidak melibatkan aktifitas siswa, belum digunakannya media pembelajaran oleh guru, sehingga aktifitas dan hasil belajar siswa menjadi rendah (Sundayana, 2015). Dituntutnya penguasaan teknologi bagi siswa, semakin terbiasanya siswa menggunakan handphone dalam kehidupan sehari-hari baik untuk bermedia sosial, bermain game serta untuk pembelajaran, sebagian siswa sudah mempunyai laptop ataupun komputer, tersedianya laboratorium komputer di sekolah, membuat peneliti tergerak untuk menggunakan sumber pembelajaran sekaligus media pembelajaran yang memudahkan siswa untuk mempelajari matematika baik di sekolah ataupun di rumah. Sehingga dikembangkanlah emodul yaitu modul dalam bentuk digital yang bisa dibaca melalui perangkat digital.

Tujuan penelitian ini untuk mengembangkan emodul format epub untuk pembelajaran matematika pada materi trigonometri, menguji keefektifannya dalam pembelajaran, serta mengetahui respon siswa terhadap penggunaan emodul trigonometri. Emodul trigonometri adalah modul berisi materi trigonometri yang bisa digunakan pada perangkat digital seperti komputer, laptop, HP, dan lainnya.

\section{METODE PENELITIAN}

Jenis penelitian ini adalah penelitian dan pengembangan (research and development / R\&D). Rancanganpenelitian dan pengembangan menggunakan model ADDIE, yang merupakan akronim dari analysis, design, development, implementation, dan evaluation. Dalam penelitian pengembangan ini yang menjadi subyek pelaku penelitian adalah peneliti yang sekaligus bertindak sebagai pengembang media. Subyek uji ahli evaluasi adalah guru matematika pada SMA Negeri 1 Pagar Alam, sedangkan rekan guru matematika pada MAN 1 Banjarmasin bertindak sebagai ahli materi. Uji coba produk dilaksanakan di kelas X IPS 1 MAN 
1 Banjarmasin sebagai kelas eksperimen dan kelas X IPS 2 MAN 1 Banjarmasin sebagai kelas kontrol. Pengumpulan data penelitian dilakukan dalam 4 tahap, yaitu pada tahap analysis, design, development, dan implementation (Sugiyono, 2015).

Pada tahap analysis, dilakukan pengumpulan data mengenai pandangan siswa terhadap mata pelajaran matematika, ketersediaan buku paket di sekolah, serta penggunaan Handphone pada siswa kelas X MAN 1 Banjarmasin melalui pengamatan dan wawancara. Pada tahap design, dilakukan pengumpulan data mengenai perangkat pembelajaran Matematika Wajib kelas X semester genap tahun pelajaran 2018/2019melalui teknik dokumentasi dan membuat produk awal (prototype) emodul trigonometri. Pada tahap development, dilakukan pengumpulan data mengenai hasil penilaian validitas dan kepraktisan emodul trigonometri dari ahli evaluasi dan ahli materi melalui angket. Pada tahap implementation, dilakukan pengumpulan data mengenai nilai ulangan harian materi trigonometri melalui tes tertulis serta untuk mengetahui respon siswa terhadap penggunaan emodul trigonometri melalui angket.

Data yang telah diperoleh dari instrumen penelitian selanjutnya dianalisis agar diperoleh kesimpulan yang mengarah pada tujuan penelitian. Teknis analisis data yang digunakan adalah teknik analisis deskriptif. Analisis data instrumen studi lapangan, hasil studi lapangan berupa hasil wawancara dengan siswa digunakan sebagai acuan untuk mengembangkan media pembelajaran yang sesuai dengan kebutuhan siswa.Analisis data instrumen penilaian ahli evaluasi dan ahli materi terhadap emodul trigonometri kelas $\mathrm{X}$ menggunakan skala Likert. Setelah lembar validasi diisi oleh 2 orang ahli lalu dibuat rekapitulasi per indikator. Masing-masing indikator diberikan skor 4 jika Sangat Baik (SB), skor 3 jika Baik (B), skor 2 jika Cukup (C) dan skor 1 jika Kurang (K). Selanjutnya dicari skor keseluruhan indikator. Skor kemudian diubah menjadi skala nilai 100 kemudian ditentukan predikat dengan rentangan sebagai berikut.

Tabel 1. Predikat Penilaian Ahli

\begin{tabular}{|c|c|}
\hline Nilai & Predikat \\
\hline $85<\mathrm{N} \leq 100$ & Sangat Baik \\
\hline $70<\mathrm{N} \leq 84$ & Baik \\
\hline $56<\mathrm{N} \leq 69$ & Cukup \\
\hline $\mathrm{N} \leq 55$ & Kurang \\
\hline
\end{tabular}

Analisis data uji efektivitas emodul, setelah divalidasi oleh ahli dan diujicobakan dalam ujicoba terbatas, selanjutnya dilakukan ujicoba dalam kelas sebenarnya menggunakan model penelitian eksperimen, dengan jenis Pre-Experimental Adapun desain penelitian eksperimen $\mathrm{O}_{1}$ adalah rerata tes hasi belajar kelas control dan $\mathrm{O}_{2}$ adalah rerata tes hasil belajar kelas eksperimen.

Pengujian dalam penelitian ini analisis datanya tidak menggunakan statistik inferensial seperti $u j i$, tetapi
Design, dengan rancangan Intact-Group Comparison. Terdapat kelompok sebagai kelas eksperimen dan kelompok sebagai kelas kontrol (Sugiyono, 2015). Sampel tidak dipilih secara random namun berdasarkan analisis kebutuhan. menggunakan statistik deskriptif (Sugiyono,2015).

Untuk mengukur pengaruh perlakuan digunakan rumus $\left(\mathrm{O}_{2}-\mathrm{O}_{1}\right)$. Analisis hasil belajar untuk menentukan keberhasilan produk berdasarkan ketuntasan hasil belajar secara klasikal. Suatu media dinyatakan berhasil jika 
banyaknya siswa yang tuntas (mencapai KKM) sesuai yang telah ditetapkan yaitu lebih dari $75 \%$ siswa. Data hasil angket respon siswa terhadap penggunaan emodul trigonometri setelah dianalisis dengan teknik analisis deskriptif selanjutnya mendeskripsikan masing-masing alternatif jawaban angket dalam bentuk persentase. Pedoman yang digunakan dalam kriteria respon siswa diadaptasi dari Khabibah (2006, dalam Sya'roni, 2016) disajikan dalam tabel berikut.

Tabel 2. Kriteria Respon Siswa

\begin{tabular}{|c|c|}
\hline Rentang Persentase (\%) & Kriteria \\
\hline $85-100$ & Sangat Positif \\
\hline $70-84$ & Positif \\
\hline $50-69$ & Kurang \\
\hline $0-50$ & Negatif \\
\hline
\end{tabular}

\section{HASIL DAN PEMBAHASAN}

Deskripsi Tahap Analysis (Analisis)

Pada tahap analysis dilakukan analisis kebutuhan pembelajaran dan karakteristik siswa (pandangan siswa terhadap mata pelajaran matematika, ketersediaan buku paket di sekolah, serta penggunaan Handphone pada siswa kelas X MAN 1 Banjarmasin), hal ini bertujuan untuk mengetahui apakah pembelajaran matematika memerlukan emodul ataupun tidak. Berdasarkan hasil pengamatan terhadap ketersediaan buku paket kelas $\mathrm{X}$ matematika wajib Kurikulum 2013 di perpustakaan sekolah ternyata masih belum banyak dan tidak memenuhi kriteria satu buku untuk satu anak. Berdasarkan hasil wawancara tentang penggunaan HP/ smartphone/ androidpada siswa kelas $\mathrm{X}$ MAN 1 Banjarmasin yang peneliti ampu yaitu kelas X IPS 1, X IPS 2, X IPS 3, dan $\mathrm{X}$ Agama 1, dari 136 orang siswa sebanyak 73,5 \% memiliki HP/smartphone/android. Dari 4 kelas yang diampu tersebut, di kelas $X$ IPS 1 hanya 2 orang siswa saja yang tidak menggunakan HP/smartphone/android.Sedangkan kelas X IPS 2 sebanyak 16 orang, X IPS 3 sebanyak 10 orang dan X Agama 1 sebanyak 8 orang. Sehingga peneliti mengambil kelas X IPS 1 sebagai kelas eksperimen dan X IPS 2 sebagai kelas kontrol.

Ditinjau dari segi minat untuk belajar matematika menggunakan emodul, di kelas X IPS 1 terdapat 96,97\% atau hanya 1 anak saja yang tidak berminat diakibatkan tidak memiliki HP. Untuk mengatasi hal tersebut, maka siswa ikut melihat dan mencoba pembelajaran menggunakan emodul menggunakan HP teman sebangku.

\section{Deskripsi Tahap Design (Perancangan)}

Kegiatan yang dilakukan pada tahap ini yaitu menyusun tes kriteria sebagai tindakan pertama untuk mengetahui kemampuan awal siswa, memilih media pembelajaran yang sesuai dengan materi dan karakteristik siswa, memilih bentuk penyajian pembelajaran disesuaikan dengan media pembelajaran yang digunakan, menyimulasikan penyajian materi dengan media dan langkah-langkah pembelajaran yang dirancang. Pada saat simulasi pembelajaran berlangsung, dilaksanakan juga penilaian dari teman sejawat.

$$
\text { E-modul trigonometri }
$$

dikembangkan berdasarkan desain materi dan desain media pembelajaran. Desain materi mengacu pada perangkat pembelajaran yaitu kalender pendidikan, rencana pekan efektif, silabus, program tahunan, program semester genap tahun pelajaran 2018/2019 mata pelajaran Matematika Wajib kelas X SMA/MA. Berdasarkan perangkat pembelajaran tersebut, materi pembelajaran yang disajikan yaitu tentang trigonometri. Sedangkan desain media pembelajaran meliputi penentuan jenis media, format 
sajian, spesifikasi minimal perangkat elektronik yang dapat mengakses emodul.

Dalam tahap perancangan, peneliti membuat produk awal (prototype) emodul trigonometri dimulai dari pembuatan kerangka emodul yang terdiri dari pendahuluan, kegiatan pembelajaran dan evaluasi sesuai dengan kerangka isi analisis kurikulum dan materi. Dilanjutkan dengan pembuatan emodul dengan format epub (Syaroni dan Amalia, 2016). Untuk membuat emodul berformat epub ini diperlukan perangkat lunak utama dan perangkat lunak pendukung. Perangkat lunak utama adalah Program Microsoft Word untuk membuat naskah modul dan aplikasi Sigil untuk membuat naskah emodul dalam format epub. Sedangkan perangkat lunak pendukung meliputi Program Microsoft Power Point untuk membuat paparan yang nantinya akan dikonversi menjadi video, Screencast untuk membuat rekaman layar laptop dan pengolah video. Peneliti menggunakan FastStone Capture dan Screen Cast O Matic untuk membuat rekaman layar dan Format Factory untuk mengubah format video. Format video yang bisa disisipkan ke dalam emodul adalah format mp4, sehingga saat peneliti membuat rekaman layar menggunakan fastStone Capture maka harus mengubahnya lagi dengan bantuan format factory agar video berformatmp4. Namun saat merekam dengan Screencast O matic maka video akan langsung berformat mp4.

\section{Deskripsi Tahap Development (Pengembangan)}

Pada tahap pengembangan ini, dilakukan langkah-langkah meliputi validasi model oleh ahli materi dan ahli evaluasi kemudian merevisi emodul berdasarkan saran dari para ahli saat validasi. Hal-hal yang divalidasi meliputi panduan penggunaan serta perangkat emodul. Ada beberapa saran dari ahli evaluasi meliputi: (1) Pada cover gambar segitiga dan nilai trigonometri sebaiknya diganti dengan konteks yang nyata, misalnya rumah adat Banjar sehingga lebih menarik dan kontekstual. (2) Penjelasan yang ada pada video dan pemaparan sebaiknya saling melengkapi bukan mengulang kembali apa yang ada di video tersebut. (3) Ukuran dan jenis huruf pada setiap paragraph sebaiknya konsisten, juga di masing-masing paragraf rata kiri kanannya sebaiknya sama. (4) Tulisan di pemaparan terlalu rapat yang akhirnya dapat mengakibatkan pembacanya (siswa) menjadi kurang minat untuk mempelajarinya. (5) PPT(powerpoint) yang dijadikan video sebaiknya backgroundnya sama sehingga tidak mengganggu pandangan pembaca dan kesannya terlalu "ramai". (6) Glosarium sebaiknya dibuat rata kiri, jika dibaca dengan Azardi masih lumayan tapi jika dibaca dengan Reasily kurang bagus. Sedangkan saran dari ahli materi yaitu materi yang ada pada video sebaiknya dibedakan dengan bahan materi yang disajikan di emodul agar para siswa mendapatkan tambahan pengetahuan tentang materi tersebut.

Berikut ini adalah tampilan emodul trigonometri format epub di Azardi yang dikembangkan melalui penelitian dan pengembangan ini.

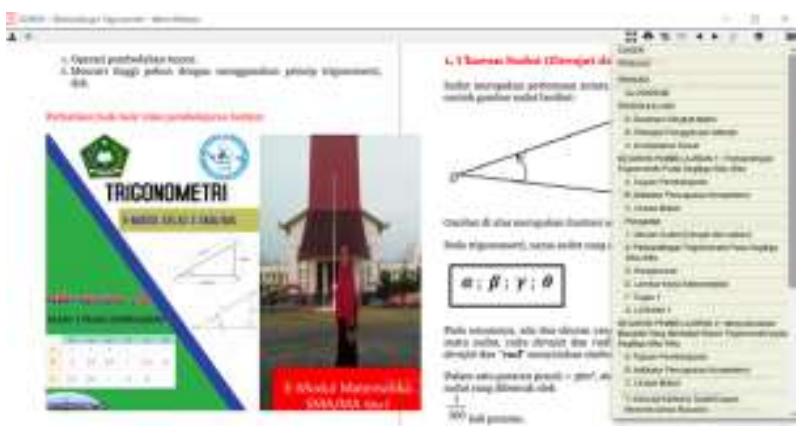

Gambar 1. Tampilan E-Modul di Azardi 


\section{Deskripsi Tahap Implementation (Implementasi)}

Untuk menjadi media pembelajaran yang layak maka perlu dilaksanakan uji coba di lapangan. Dalam hal ini peneliti melakukan ujicoba terbatas emodul dalam pembelajaran terhadap 7 orang siswa kelas $X$ IPS 1.Ujicoba terbatas dilakukan di luar jam pelajaran matematika. Kemudian dilakukan revisi emodul berdasarkan hasil ujicoba. Sesudah direvisi kemudian peneliti mengujicobakan e-modul pada seluruh siswa di kelas X IPS 1 selama 4 kali pertemuan tatap muka. Selama ujicoba skala luas ini peneliti menguji efektifitas emodul trigonometri dengan eksperimen, yaitu membandingkan hasil tes siswa kelas X IPS 1 sebagai kelas eksperimen ujicoba emodul trigonometri dengan kelas X IPS 2 sebagai kelas kontrol yang menggunakan pembelajaran biasa tanpa menggunakan emodul trigonometri.

Berikut gambar pelaksanaan penggunaan emodul trigonometri di Kelas X IPS 1.

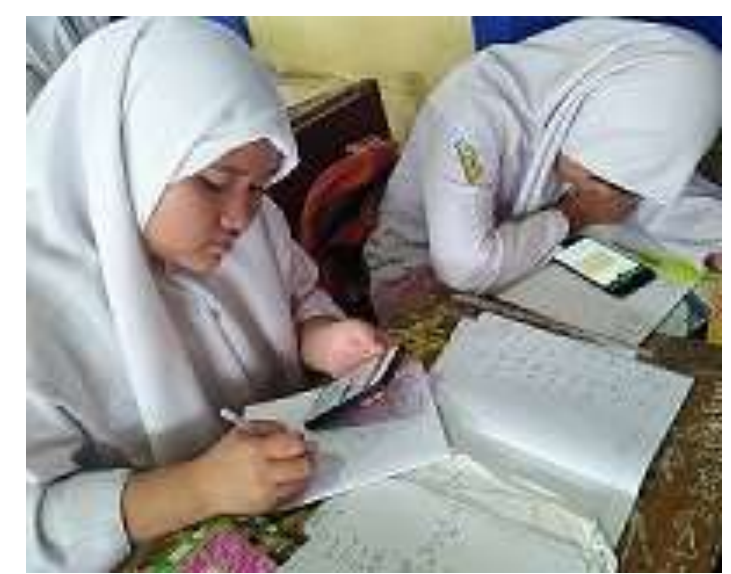

Gambar 2. Uji Coba E-Modul Trigonometri

Deskripsi Tahap Evaluation (Evaluasi Akhir)

Tahap evaluasi dalam penelitian pengembangan ini terdiri dari tiga kegiatan evaluasi yaitu: (a) Kegiatan evaluasi 1, merupakan evaluasi hasil angket respon siswa terhadap emodul trigonometri, diperoleh bahwa mayoritas siswa kelas $\mathrm{X}$
IPS 1 berminat belajar matematika dengan menggunakan emodul. (b) Kegiatan evaluasi 2, merupakan evaluasi hasil angket penilaian validitas oleh ahli untuk mengetahui apakah emodul trigonometri dinyatakan valid dan dapat diujicobakan di lapangan atau tidak.Adapun hasil validasi sebagai berikut.

Tabel 3. Hasil Validasi Emodul Trigonometri

\begin{tabular}{|c|c|}
\hline Validator & Hasil Validasi \\
\hline Ahli Evaluasi & 87,50 \\
\hline Ahli Materi & 83,33 \\
\hline Rata-rata & 85,42 \\
\hline
\end{tabular}

Dari tabel diatas, rata-rata ahli evaluasi dan ahli materi yaitu 85,42 termasuk kategori baik. Sehingga emodul trigonometri memiliki kriteria layak, dapat dijadikan sebagai penunjang proses belajar siswa yang dapat digunakan secara mandiri. (c) Kegiatan evaluasi 3, merupakan evaluasi akhir terhadap emodul trigonometri yaitu untuk mengetahui apakah memenuhi aspek efektif atau tidak. Penilaian dilakukan berdasarkan hasil tes siswa pada materi trigonometri serta hasil angket respon siswa 
terhadap penggunaan emodul trigonometri. Didapat rata-rata hasil tes siswa kelas X IPS 1 yaitu 84,58 sedangkan rata-rata hasil tes siswa kelas X IPS 2 yaitu 66,32. Dengan demikian e-modul trigonometri dikategorikan efektif dalam pembelajaran dengan perbedaan selisih rata-rata kelas eksperimen dan kelas kontrol sebesar 18,26. Ketuntasan klasikal kelas eksperimen sebesar $84,85 \%$ siswa tuntas atau mencapai KKM, sedangkan ketuntasan kelas kontrol

\section{PENUTUP}

Hasil yang diperoleh dari penelitian ini : (1) Emodul trigonometri dinyatakan valid oleh ahli dengan nilai 85.42 kategori sangat baik, (2) Emodul trigonometri dinyatakan efektif dalam pembelajaran dengan perbedaan selisih rata-rata nilai tes antara kelas eksperimen dan kelas kontrol sebesar 18,26. Untuk ketuntasan klasikal kelas eksperimen sebesar $84,85 \%$ siswa tuntas atau mencapai KKM, (3) Hasil respon siswa terhadap penggunaan emodul trigonometri sebesar $81,82 \%$ termasuk

\section{DAFTAR PUSTAKA}

Darsono, 2017. Pengembangan Media Pembelajaran Matematika Berbasis Ms. Excel Dengan Vba Pada Materi Matriks.Prosiding Seminar Nasional Pendidikan Matematika, 103 - 112.

Prastowo, A. 2012.Panduan Kreatif Membuat Bahan Ajar Inovatif.Jogjakarta: Diva Press.

Rohman, M. F. 2018. Pengembangan Emodul Format Epub Sebagai Media Pembelajaran Kaidah Pencacahan. Naskah Laporan Lomba Inovasi

Sugiyono, Metode Penelitian Kuantitatif, yaitu 44,12\%. Hasil respon siswa terhadap penggunaan emodul trigonometri sebesar $81,82 \%$ termasuk kategori baik. Oleh karena memenuhi kriteria valid dan efektif maka emodul format epub untuk pembelajaran matematika pada materi trigonometri kelas X MAN 1 Banjarmasin dinyatakan layak, dapat dijadikan sebagai penunjang proses belajar siswa yang dapat digunakan secara mandiri.

kategori baik. Secara keseluruhan, emodul trigonometri memiliki kriteria layak, dapat dijadikan sebagai penunjang proses belajar siswa yang dapat digunakan secara mandiri. Produk emodul yang dihasilkan dapat dijadikanalternatif media pembelajaran bagi guru dalam pembelajaran matematika khususnyamateri trigonometri, serta dapat dikembangkan lagi baik dari segi tampilan, maupun konten yang termuat di dalamnya,serta menjadi kajian yang menarik untuk dilanjutkan bagi praktisi maupun guru matematika.

Kualitatif Dan $R$ \& D, 28th Edn (Bandung: Alfabeta, 2018)

Sundayana, R. 2015.Media Dan Alat Peraga Dalam Pembelajaran Matematika.Bandung: Alfabet.

Sya'roni. A. R Dan Amalia, R. 2016. Pengembangan Program Aplikasi Mathematics Mobile Learning Berbasis Android Sebagai Media Pembelajaran Matematika Wajib Kelas X Sekolah Menengah Atas.Jurnal Edukasi Matematika, 7, 799-807. 